\title{
CONF-970794--1
}

\section{Performance Evaluation and Optimization of a Fast Tool Servo for Single Point Diamond Turning Machines}

\author{
Arthur C. Miller, Jr. and James F. Cuttino \\ Oak Ridge National Laboratory, Oak Ridge, Tennessee 37831-8039 \\ The University of Alabama, Tuscaloosa, Alabama 35487-0276
}

\begin{abstract}
This paper describes a new, fast tool servo system designed for fabrication of non-rotationally symmetric components using single point diamond turning machines. A prototype device, designed for flexible interfacing to typical machine tool controllers, will be described along with performance testing data of tilted flat and off-axis conic sections. Evaluation data show that servo produced surfaces have an RMS roughness less than 175 angstroms (2-200 $\mu \mathrm{m}$ spatial filter). Techniques for linearizing the hysteretic effects in the piezoelectric actuator are also discussed. The nonlinear effects due to hysteresis are reduced using a dynamic compensator module in conjunction with a linear controller. The compensator samples the hysteretic voltage/displacement relationship in real time and modifies the effective gain accordingly. Simulation results indicate that errors in the performance of the system caused by hysteresis in the system can be compensated and reduced by $90 \%$. Experimental implementation results in an $80 \%$ reduction in the motion error caused by hysteresis, but peak-to-valley errors are limited by side effects from the compensation. The uncompensated servo system demonstrated a peak-to-valley error of less than 0.80 micrometer for an off-axis conic section turned on-axis.
\end{abstract}

Keywords: Diamond Turning, SPDT, Fast Tool Servo, Ultraprecision Control System, Anamorphic Optics

\section{INTRODUCTION}

Diamond single point turning has found broad application in the area of optical surface generation. In the 1970s and 1980s, machines were fabricating surfaces for use in the infrared. Advances in machines and tooling in the late 1980s and 1990s enabled diamond turned reflective optics that are suitable for use at visible wavelengths. ${ }^{1}$ With the advent of improved machines and processes, interest has been growing for a fast tool servo mechanism (FTS) to increase the capability and capacity of existing machines.

Many of the earlier FTS systems were used to correct various machine related errors such as spindle runout or parasitic vibrations. ${ }^{2,3}$ New adaptations of fast travel mechanisms with very high resolution and stiffness have addressed these needs as well as creating challenging new areas of application. 4,5,6 Ultraprecision surfaces that are now possible include unique, non-rotationally symmetric components such as correcting secondary mirrors, anamorphic optics, off-axis conic sections turned on-axis and generalized surfaces.

This paper describes a device designed to extend the capacity of existing machines for the production of far off-axis conic sections. To produce off-axis optical elements on the axis of rotation, the FTS moves the cutting tool in and out of the plane of optic being machined twice per revolution in a roughly sinusoidal manner. The solution greatly reduces the required machine size when the optical element is small enough to fit on the machine but requires a large swing capacity to manufacture its parent surface. A fast tool servo system allows the machine to operate near the center of its capacity thus improving the accuracy, repeatability, and smoothness of the resulting surface. Also, such fabrication schemes avoid the large, difficult to balance fixtures that decrease loop stiffness in critical machining operations near the extremes of slide travel.

Tilted and eccentric pupil systems are increasingly being used in advanced systems to enhance performance and avoid diffraction effects caused by obscurations in reflective and catadioptric concentric systems. Such systems, used in conjunction with self-aligning designs, are very amenable to production with ultraprecise diamond turning machines. Broad application is found in industrial, scientific, and military systems including interceptor-class optical systems, scientific instruments, and space-based optical platforms and analyzers.
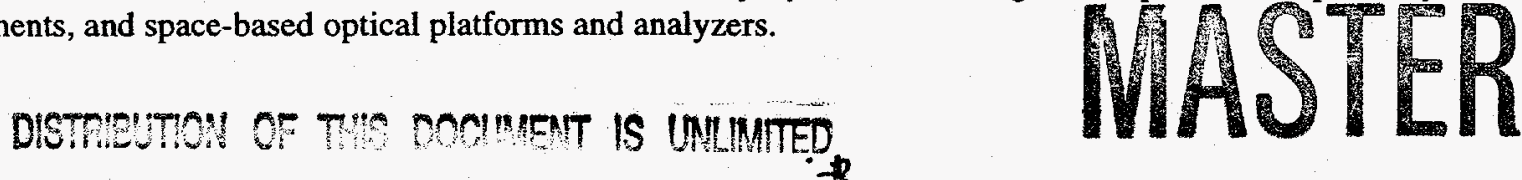


\section{ACTUATOR DESCRIPTION}

The FTS system actuator was designed by the Precision Engineering Center of North Carolina State University. The device, shown in Figure 1, is based on an earlier version with a much smaller travel and is comprised of a stiffened piezoelectric transducer (PZT) stack made from lead zirconate titaniate. Salient features of the design include the use of a highresolution/bandwidth closed-loop capacitance feedback probe, long PZT stack for extended travel, and an active cooling system to remove hysteretic heating. Flexure plates provide high radial stiffness while allowing the required axial movement. Diamond tipped tools with short shank adapters are used in the tool holder to machine the surfaces. The installed actuator system is shown in Figure 2 machining a copper tilted flat on-axis. Also included but not shown are the coolant and control systems. ${ }^{7}$ A summary of important system specifications are listed in Table 1.

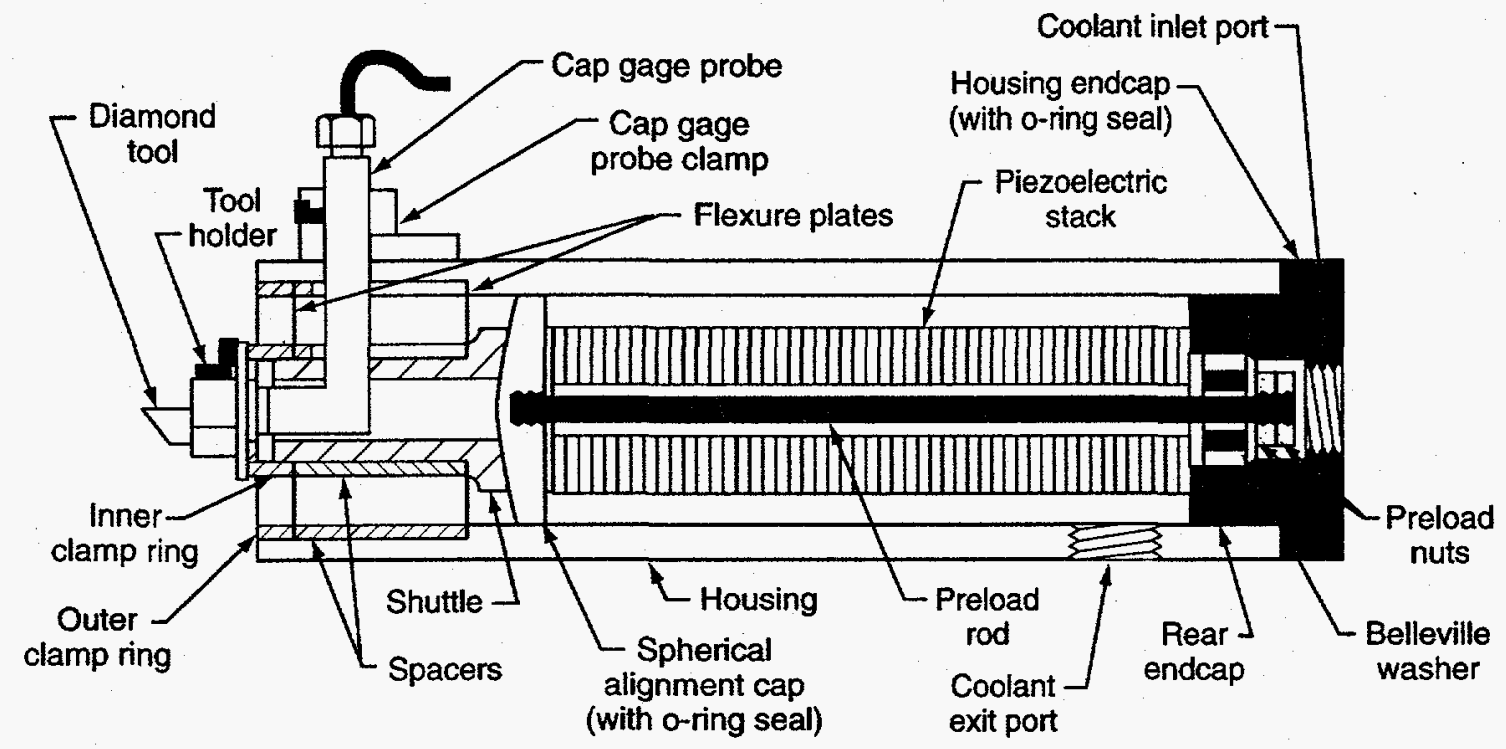

Figure 1. Fast Tool Servo System

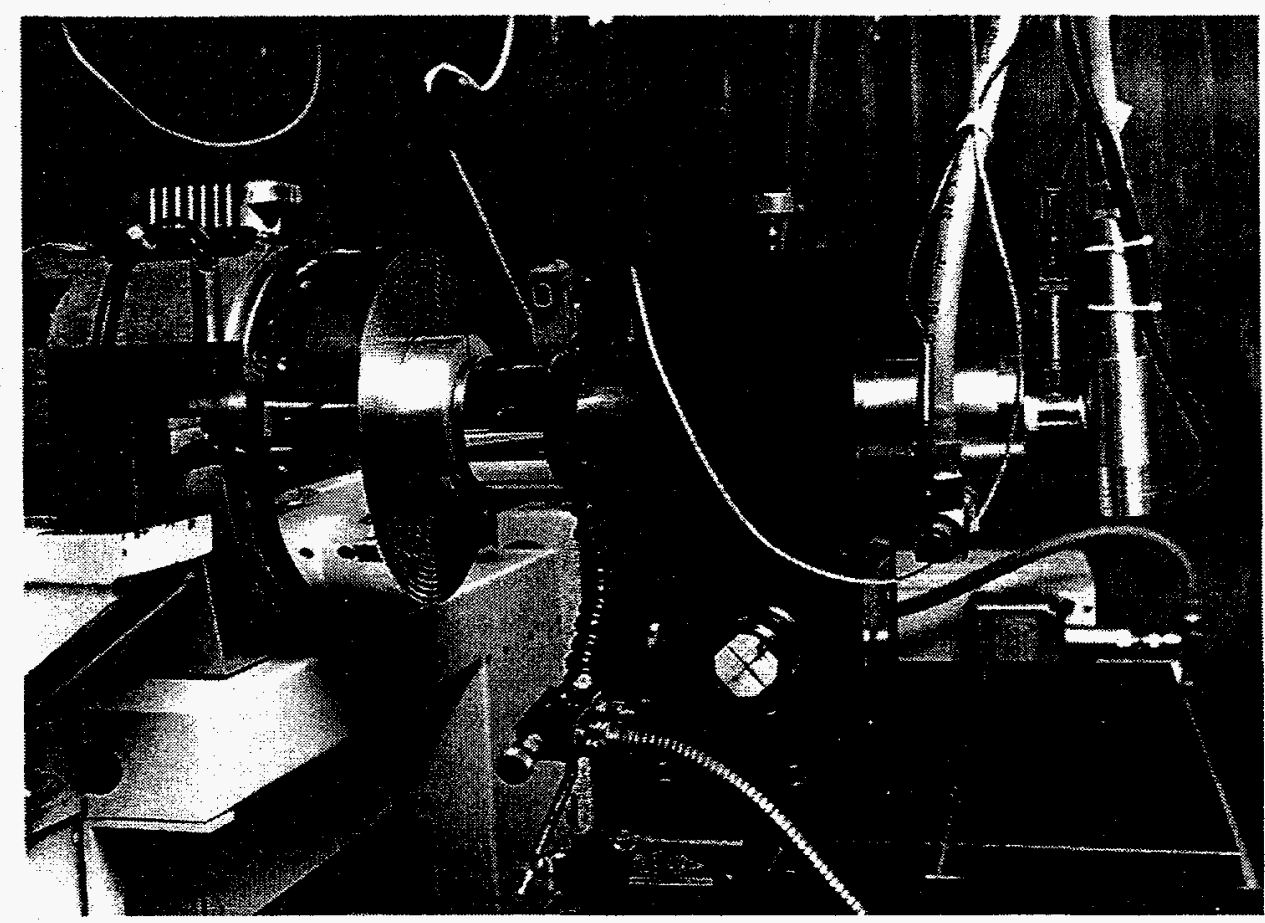

Figure 2. Installed Fast Tool Servo System 
Table 1. Important FTS system specifications

\begin{tabular}{|l|l|}
\hline Update Speed & 100 microsecond \\
\hline Resolution & 0.025 micrometers \\
\hline Measured Accuracy & 0.8 micrometers \\
\hline Reproducibility & 0.2 micrometers \\
\hline Operating range & 100 micrometers \\
\hline Bandwidth & $100 \mathrm{hz}$ \\
\hline
\end{tabular}

\section{PERFORMANCE TESTING}

Evaluation of the FTS system was accomplished in three phases using a Nanoform 600 diamond turning machine. First, the smoothness of the surface produced by the FTS was characterized under various operating conditions. Form accuracy was then determined by machining a flat that was tilted with respect to the machine cross slide as described below. The final phase involved production of an off-axis parabolic mirror segment machined on-axis.

\section{Surface smoothness evaluation}

Surface finish was evaluated for the conditions listed in Table 2. To minimize material effects, the evaluation was made with copper tilted flats. The roughness measurements were taken perpendicular to the machining grooves with a Chapman MP2000 non contact profilometer over a spatial bandwidth of 2 to $200 \mu \mathrm{m}$. As can be seen in the table, no significant change in surface roughness is noticed until closed loop control is activated. The relatively rough surface produced by the FTS is largely due to the $254 \AA$ resolution limitation of the feedback capacitance probe. Although the present resolution is sufficient for position accuracy at bandwidths of $100 \mathrm{hz}$, much smoother surfaces could be produced if an order of magnitude increase in resolution were achievable.

Table 2. Roughness evolution of the fast tool servo under various operating conditions

\begin{tabular}{||l|c|}
\hline \multicolumn{1}{|c|}{ Condition } & $\begin{array}{c}\text { RMS Surface Roughness } \\
(\mathbf{A}: 2-200 \mu \mathrm{m})\end{array}$ \\
\hline Reference & 112 \\
\hline FTS off & 88 \\
\hline Open loop control at $500 \mathrm{~V}$ & 98 \\
\hline Open loop control tilted flat, $60 \mu \mathrm{m}$ travel & 111 \\
\hline $\begin{array}{l}\text { Closed loop control tilted flat, } 100 \mu \mathrm{m} \text { travel } 1000 \mathrm{rpm}, \\
5 \mu \mathrm{m} / \mathrm{rev}\end{array}$ & 156 \\
\hline
\end{tabular}

\section{Form accuracy evaluation}

Initial surface accuracy tests were performed on the tilted flats with a phase measuring interferometer at a variety of spindle speeds and FTS travel. To cut the tilted flat, a sinusoidal displacement with the same frequency as the spindle rotation is commanded to the FTS. The amplitude is decreased linearly as the tool approaches the center of the workpiece generating a flat surface whose normal axis is tilted from the axis of rotation. The tilted flat serves as an excellent test piece because it requires full motion of the FTS and the flat surface is easy to measure using laser interferometry. Table 3 summarizes the $\mathrm{P}-\mathrm{V}$ accuracy of the resulting surfaces. Spindle speed and the decrease in system response time are the anticipated drivers. As the spindle speed is reduced from 2000 to $500 \mathrm{rpm}$ the accuracy improves from $1.0 \mu \mathrm{m}$ to $0.6 \mu \mathrm{m}$. 
Table 3. Surface form accuracy of the fast tool servo machining tilted flats on-axis

\begin{tabular}{|l|c|c|c|}
\hline \multicolumn{1}{|c|}{ Substrate } & Spindle(RPM) & FTS Travel $(\boldsymbol{\mu m})$ & P.V Accuracy $(\boldsymbol{\mu m})$ \\
\hline Copper tilted flat & 2000 & 100 & 1.0 \\
\hline Copper tilted flat & 2000 & 90 & 0.8 \\
\hline Copper tilted flat & 500 & 100 & 0.6 \\
\hline
\end{tabular}

To demonstrate the FTS system in fabricating an off-axis conic mirror on-axis, the primary mirror for an advanced design was chosen that is typical for planned military interceptor missiles. Although actual mirrors would be lightweighted, a solid substrate was used to accurately measure the effects of the FTS alone. Fixturing for the substrate also is very influential in evaluating figure accuracy. A three point mount was designed using opposing tooling balls in a groove, cone, and flat configuration for minimum distortion caused by generated moments and is shown in Figure 3.

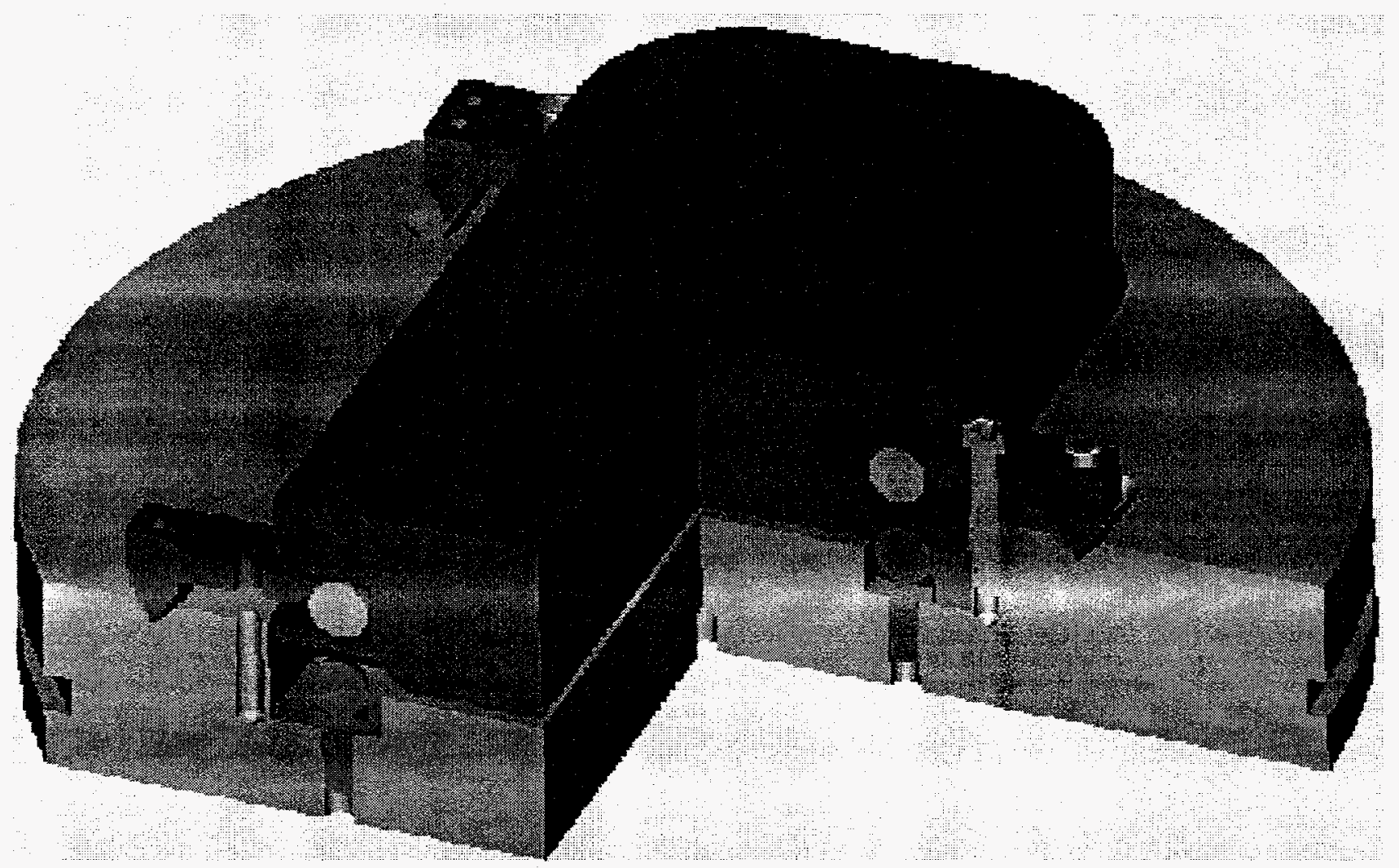

Figure 3. Fixturing for the off-axis parabola turned on-axis

The substrate was premachined to its best fit sphere and diamond turned as a sphere to establish a baseline for the process. Although great care was exercised in the machining, tool selection and setup, the resulting surface form error of the best fit sphere was found to be $0.2 \mu \mathrm{m}$. An improvement to the 3 point mount design was suggested through subsequent modeling. The analysis called for the groove to be directed toward the center of rotation rather than horizontal.

The best fit rotationally symmetric asphere was next machined into the mirror, and the FTS system was activated to machine the non-rotationally symmetric parabolic segment on-axis. A double pass interferometric null test was used to evaluate the figure accuracy of the mirror. The total peak-to-valley accuracy was determined to be $1.0 \mu \mathrm{m}$. Subtracting the best fit sphere accuracy shows that the error introduced by the fast tool servo motion was less than $0.8 \mu \mathrm{m}$. The surface error map is shown in Figure 4, and a photograph of the finished mirror is shown in Figure 5. 


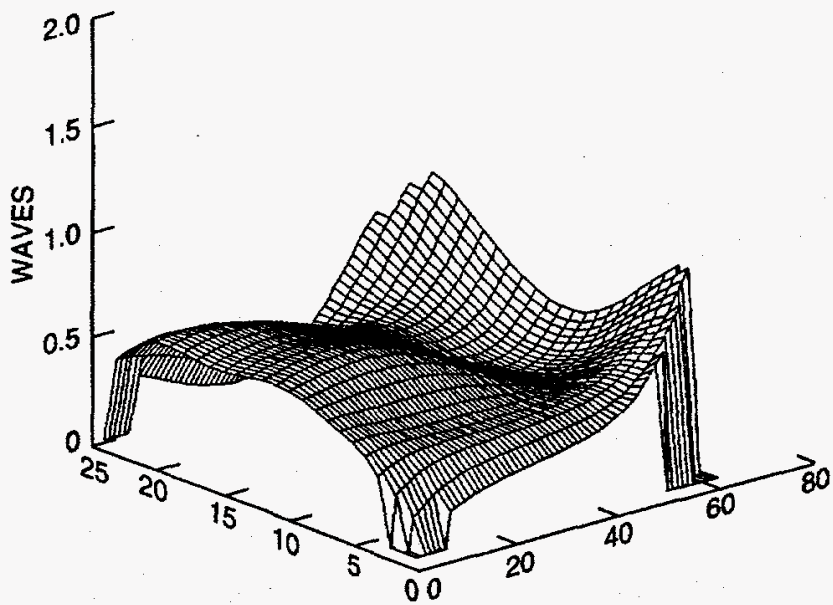

Figure 4. P-V error due to FTS motion - $0.82 \mu \mathrm{m}$

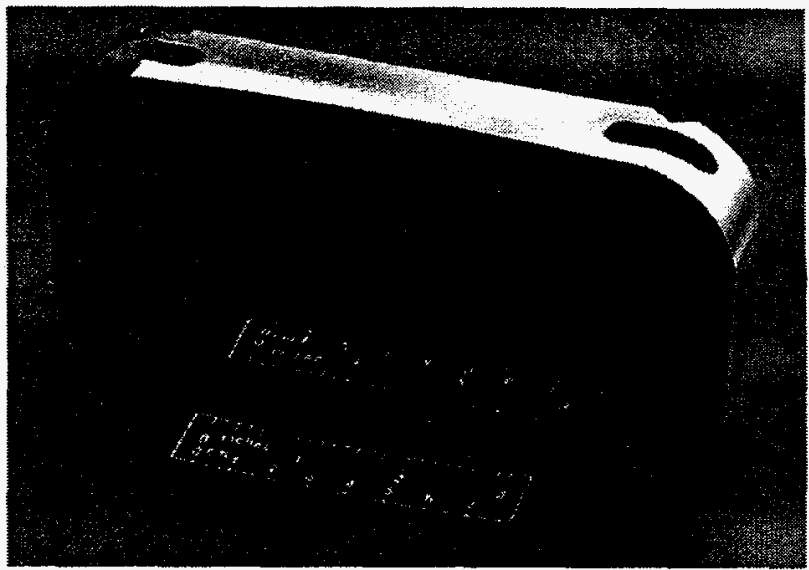

Figure 5. Off-Axis Parabola

Surface finish of the off-axis parabola was significantly worse than found in the earlier evaluation. Whereas the surface finish studies would predict a lower value, vibration caused by the undamped 3 point mount resulted in an RMS roughness of $490 \AA$.

\section{PERFORMANCE ENHANCEMENT}

Optimization of the performance of the MAC-100 Fast Tool Servo was performed in four areas, including a baseline checkout, a study in cutting parameters, improvement in control gains, and improvement using a hysteresis linearization module. Significant improvement in performance was found by optimizing the controller gains and by implementing the hysteresis linearization module. However, both techniques still result in residual form errors that take on very different forms. The cutting parameter study also indicated that, although the form error improves with decreasing spindle speed, it does so nonlinearly. Testing was conducted on $50 \mathrm{~mm}$ diameter, stress relieved aluminum tilted flats.

\section{Baseline Checkout}

A baseline checkout was conducted to analyze the performance of the MAC-100 FTS. The baseline test was cut at $1000 \mathrm{rpm}$ with a feedrate of $5 \mathrm{~mm} / \mathrm{min}$ and a cutting depth of $4 \mu \mathrm{m}$. The baseline controller runs at $10 \mathrm{kHz}$ sampling frequency using an integral controller.

Figure 6 is an interferogram of the tilted flat machined with the baseline controller. The interferogram shows a three-lobed form error across the part with a peak-to-valley (P-V) amplitude of approximately 1.4 waves, or $0.89 \mu \mathrm{m}$. The angles shown on Figure 6 represent the spindle encoder angle, $\phi$, when the tool is in that region of the workpiece. The arrangement of peaks and valleys is non-symmetric, with peaks at approximately $80^{\circ}, 210^{\circ}$, and $315^{\circ}$, and valleys at $35^{\circ}, 150^{\circ}$, and $260^{\circ}$.

\section{Improvement In Control Gains}

A generic controller routine was developed which enabled debugging of the controller gains and implementation of different controller concepts. The routine allows the user to input gains from a variety of controller techniques including PID, lead/lag, and zero/pole placement. It also has an option to dynamically linearize the system to reduce the effects of hysteresis in the piezoelectric actuator. One significant drawback to the controller is that the sampling speed must be reduced from the default of $10 \mathrm{kHz}$ to either $8 \mathrm{kHz}$ or $5 \mathrm{kHz}$ depending on the computations made by the controller. Reducing the sampling speed increases the form error, but it also enables the debugging of the controller. Once debugged, the sampling rate can be increased depending on the amount of additional computations necessary by the chosen controller technique. The default controller running at $5 \mathrm{kHz}$ sampling speed resulted in a form error of 1.6 waves, or $1.01 \mu \mathrm{m}$. 


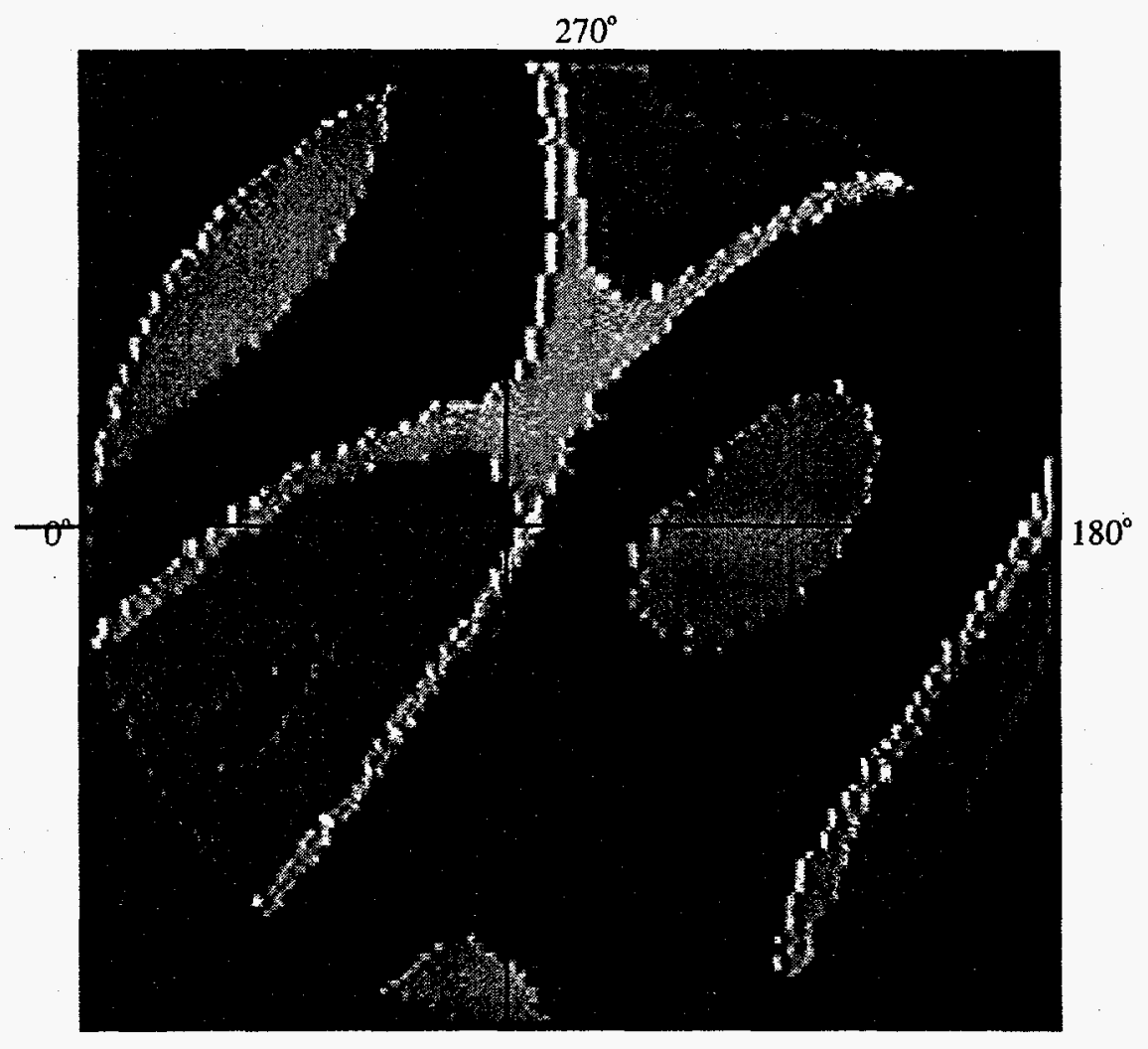

$90^{\circ}$

Figure 6. Interferogram Showing Form Error in the Benchmark Tilted Flat

Utilizing the new controller, new gains were determined for the FTS using two methods. The first method utilized a mathematical model obtained from an experimental transfer function of the FTS. The model was entered into a MATLAB program and a PID controller was designed by maximizing the bandwidth of the system. Several tests were conducted to analyze the changes, and significant improvement resulted in reducing the system hysteresis as shown in Figure 7. The plots represent the relationship between the commanded displacement signal and the actual output displacement. As shown in the figure, the new controller greatly reduced the hysteretic losses in the response. Unfortunately, the form error in the parts still exhibited the three-lobed configuration, with a peak-to-valley error of 1.4 waves, or $0.89 \mu \mathrm{m}$. This represents a $13 \%$ reduction in form error. An important component of these results, however, is the fact that the new controller was running at a reduced sampling rate of $5 \mathrm{kHz}$. Even though the form error is significant, it is still less than $1 \%$ of the total displacement.

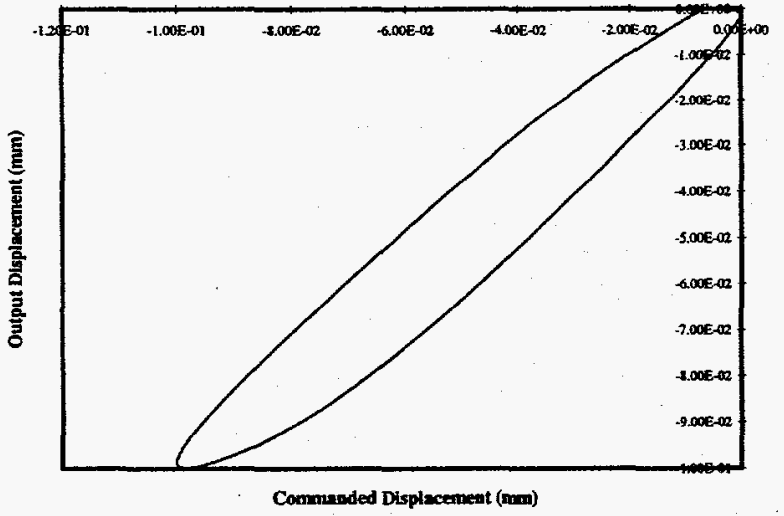

a) Existing Integral Controller

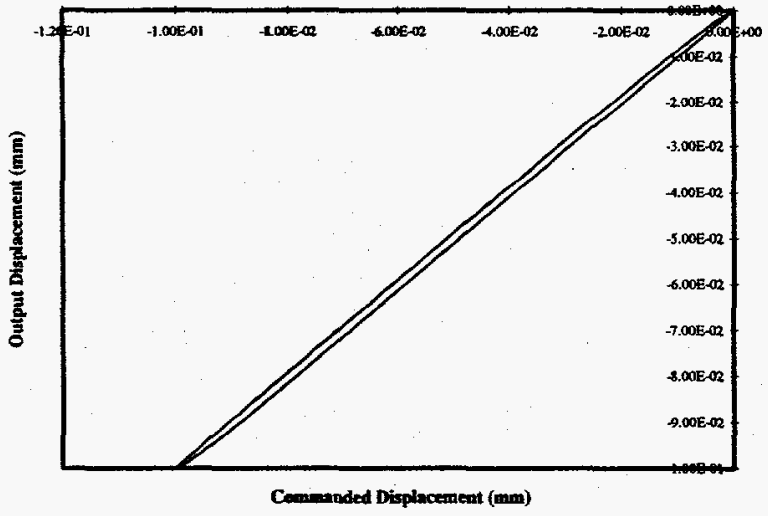

b) Optimized PID Controller

Figure 7. System Hysteresis 
The second method used for optimizing the controller was to progressively increase the PID gains while monitoring the response of the FTS on an oscilloscope. This step was executed on a streamlined version of the controller code running at $8 \mathrm{kHz}$. The proportional gain was initially increased to a maximum value that did not result in oscillations. The following error was then reduced by increasing the integral gain until the system went unstable and then reducing it to regain stability. This resulted in an oscillatory response, which was damped by increasing the derivative gain. This approach proved to be highly successful, resulting in a P.V form error of only 0.68 waves $(0.43 \mu \mathrm{m})$. This represents a $51 \%$ improvement in the form error.

\section{Study of Cutting Parameters}

The effects of changing cutting parameters were also studied. The principal parameter that was studied is the spindle speed (rpm), which affects both cutting time and form error. The amplitude of the FTS motion was kept at the maximum travel of $100 \mu \mathrm{m}$ since the tilted flat program required the amplitude to decrease to zero as the tool approached the center of the workpiece. The effect of reducing the FTS travel can therefore be extracted from any tilted flat. These tests were conducted using both of the modified PID controllers on the MAC-100, and the results were normalized to the form errors at $1000 \mathrm{rpm}$ for each controller. This normalization removed the effects of the controllers and isolated the effects of the spindle speed.

Figure 8 shows that the performance of the FTS improves with slower spindle speeds. The speeds were varied between $2000 \mathrm{rpm}$ and $100 \mathrm{rpm}$. All parameters but spindle speed were kept constant for each of the tests except for the $100 \mathrm{rpm}$ case, in which the feedrate was reduced to prevent excessively large chip sizes. Since finish was not as important as form error in these tests, the feedrate should have very little effect on the results. The vertical axis represents the ratio between the measured form error at that speed and the form error of a part cut with the same controller at $1000 \mathrm{rpm}$. The ratio decreases from 2 at $2000 \mathrm{rpm}$ to 0.65 at $100 \mathrm{rpm}$, and the trend appears to follow a second order polynomial. The form error therefore decreases with spindle speed but in a nonlinear fashion, indicating that simply reducing the speed will not necessarily eliminate the form error. Another limiting factor in reducing spindle speed is the time necessary to complete a cut, which becomes more of a factor when mass producing parts. Examination of the interferograms also indicated that the form error is somewhat independent of the range of motion of the FTS, since large errors occur even near the center of the workpiece (where the FTS motion approaches zero).

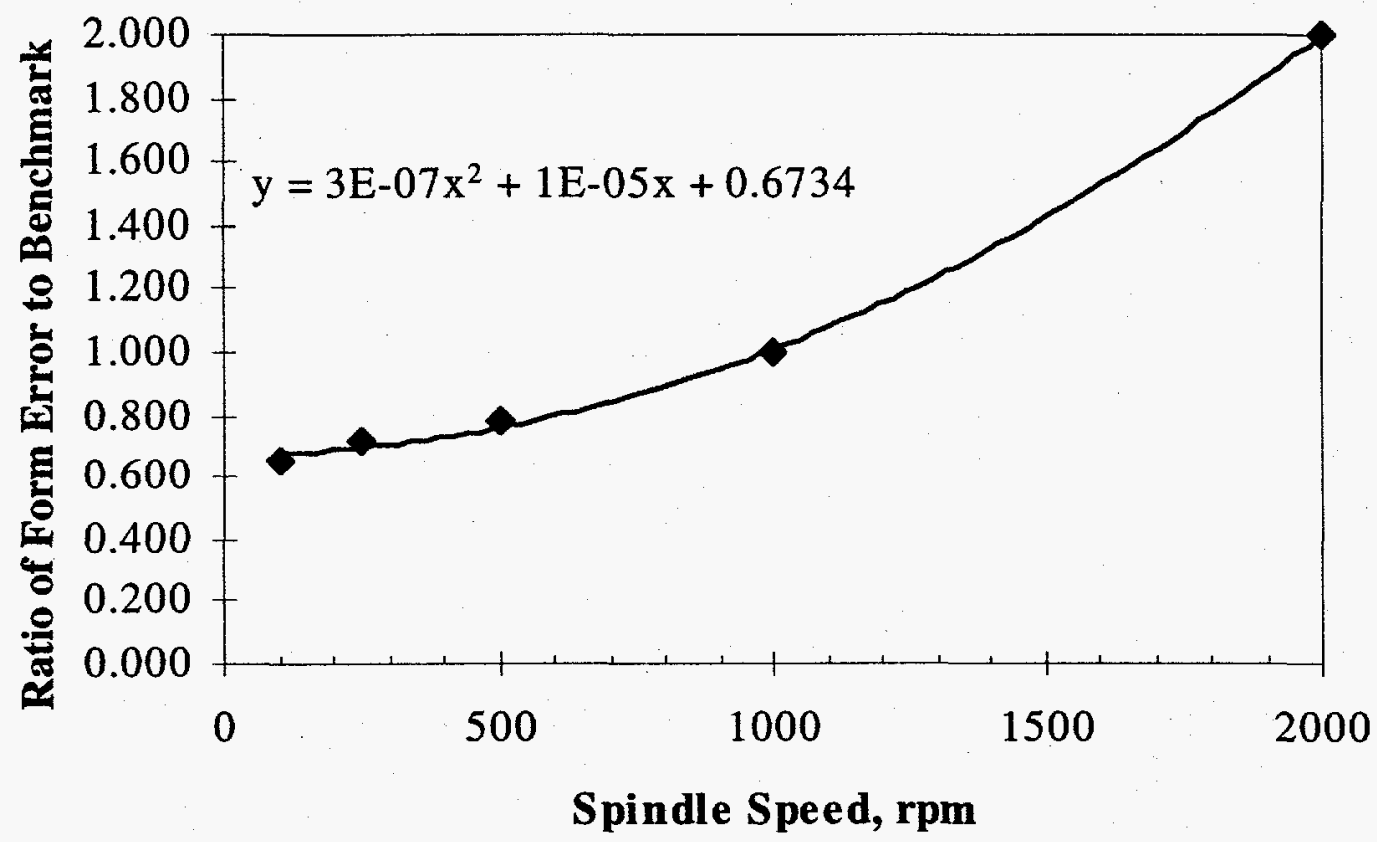

Figure 8. Effect of Spindle Speed on Form Error 


\section{Improvement Using A Hysteresis Linearization Module}

Significant effort was expended on developing and optimizing a linearization module to compensate for hysteresis in the piezoelectric actuator. The module samples the commanded voltage to the piezoelectric and the corresponding output displacement to compute the instantaneous slope of the hysteresis curve. By comparing the instantaneous slope to the desired linear slope, a compensation factor is determined and applied to the commanded input. This technique is shown in Figure 9. The instantaneous gain (or hysteresis) was measured using the previous command to the $D / A$ converter as input and the PZT displacement (measured with the capacitance gage) as output.

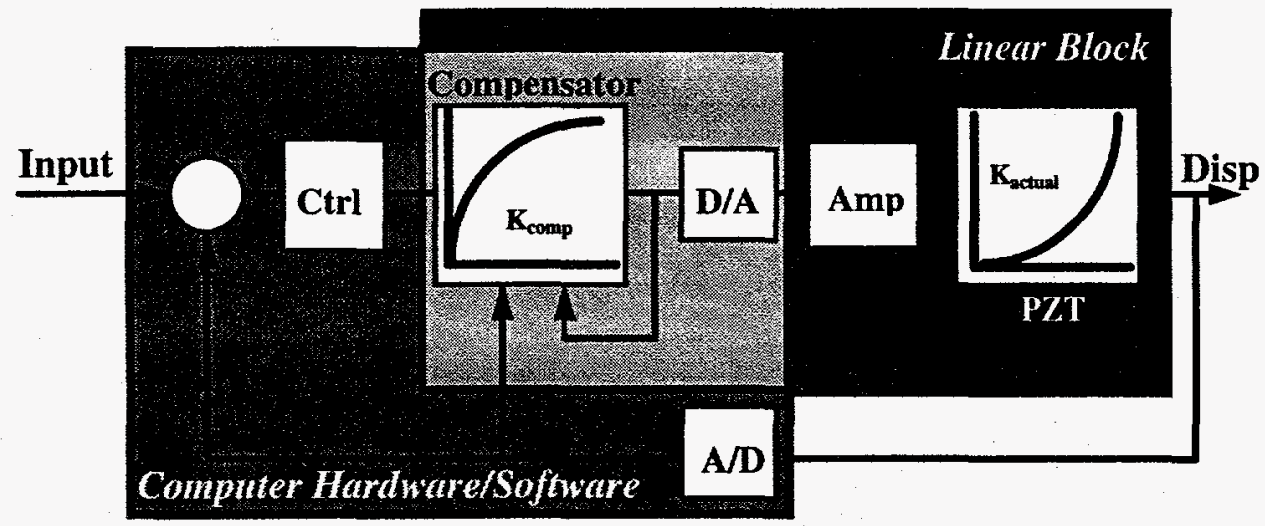

Figure 9. Block Diagram of Compensation Scheme for the MAC-100 Actuator

Comparison tests were run between the uncompensated integral controller (unmodified) at $5 \mathrm{kHz}$ sampling rate and the compensated controller. Without compensation, the error in the workpiece cut with uncompensated integral control had a peak-to-valley form error of 2.4 waves $(1.5 \mu \mathrm{m})$ at $1000 \mathrm{rpm}$. The shape of the form errors is almost identical to that shown in Figure 6. Note that this error was exaggerated due to the use of the integral controller rather than the optimized controller, but it also made it easier to determine the success of the compensation loop.

Figure 10 compares the hysteresis in the system as seen by the controller. Referring to Figure 9, this hysteresis is a plot of the output displacement vs. the output from the controller. Without the compensation, the hysteresis in the piezoelectric is dominant as shown in Figure 10a. Addition of the compensator reduced the hysteresis significantly as shown in Figure 10b, with most of the nonlinearity occurring at the end of travel. The hysteretic error is reduced to approximately $5 \mu \mathrm{m}$, or $5 \%$ of the total travel. Part of the error at the reversal is due to the compensator which amplified the controller signal past the maximum value of 10 volts, thereby clipping the signal. Also, the compensation ratio changes suddenly on reversal, which may add to the reversal error. These problems were corrected in subsequent tests.

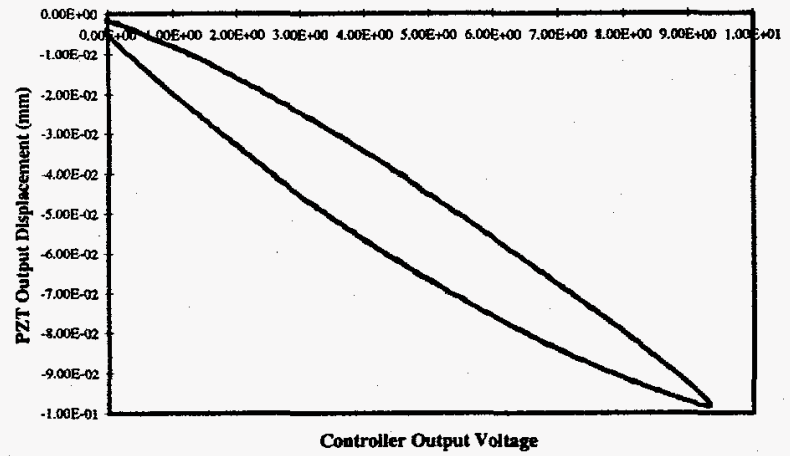

a) Before Compensation

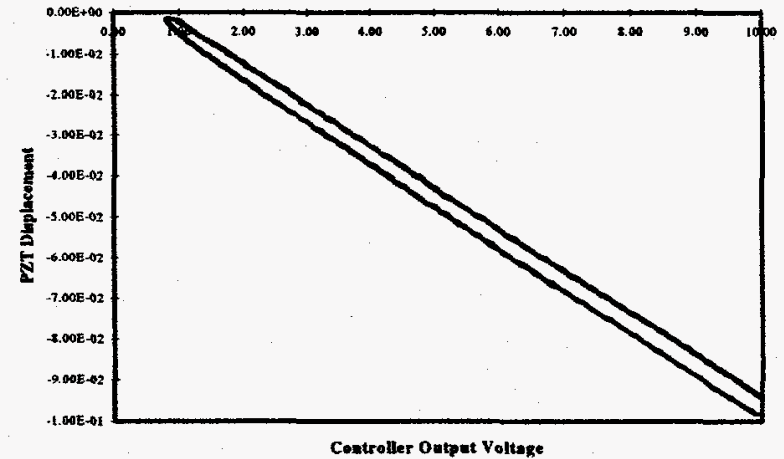

b) After Compensation

Figure 10. Comparison of System Nonlinearity Before and After Compensation 
Figure 11 shows an interferogram of a tilted flat cut using the MAC-100 with compensation. The peak-to-valley form error has been reduced from 2.4 waves $(1.5 \mu \mathrm{m})$ in Figure 11 to 1.38 waves $(0.89 \mu \mathrm{m})$, representing a $43 \%$ improvement. This technique has successfully reduced the system hysteresis to less than $5 \%$ as seen by the controller. It has resulted in a much flatter tilted flat across a limited region of the part representing a $70 \mu \mathrm{m}$ extension of the FTS. At this range of motion, the form error has been recorded as low as 0.25 waves, or $0.16 \mu \mathrm{m}$. Unfortunately, a significant artifact remains in the part that resembles a sharp valley starting on the perimeter of the part and crossing through the center of the part, becoming a sharp peak on the other side. Although the overall part contains less form error, the abruptness of the anomaly is undesirable for an optical element.

A final error remains in the tilted flat and crosses the part diagonally from $80^{\circ}$ to $260^{\circ}$. This error is probably due to the sudden change in compensation that occurs on reversal when the error signal is still non-zero. This results in the PZT remaining extended too long at $90^{\circ}$, creating a "valley" at $\sim 80^{\circ}$ (the part rotates in a counter-clockwise direction). Similarly, remaining retracted too long at $270^{\circ}$ results in a "ridge" at $\sim 260^{\circ}$. Both the ridge and the valley are seen in Figure 11, and similar results were seen in simulation.

Limited efforts were made to combine the improved PID controller gains with the nonlinear compensation module. Unfortunately, the new controller apparently affected the compensation module adversely, perhaps due to noise generation and significantly reduced phase lag.

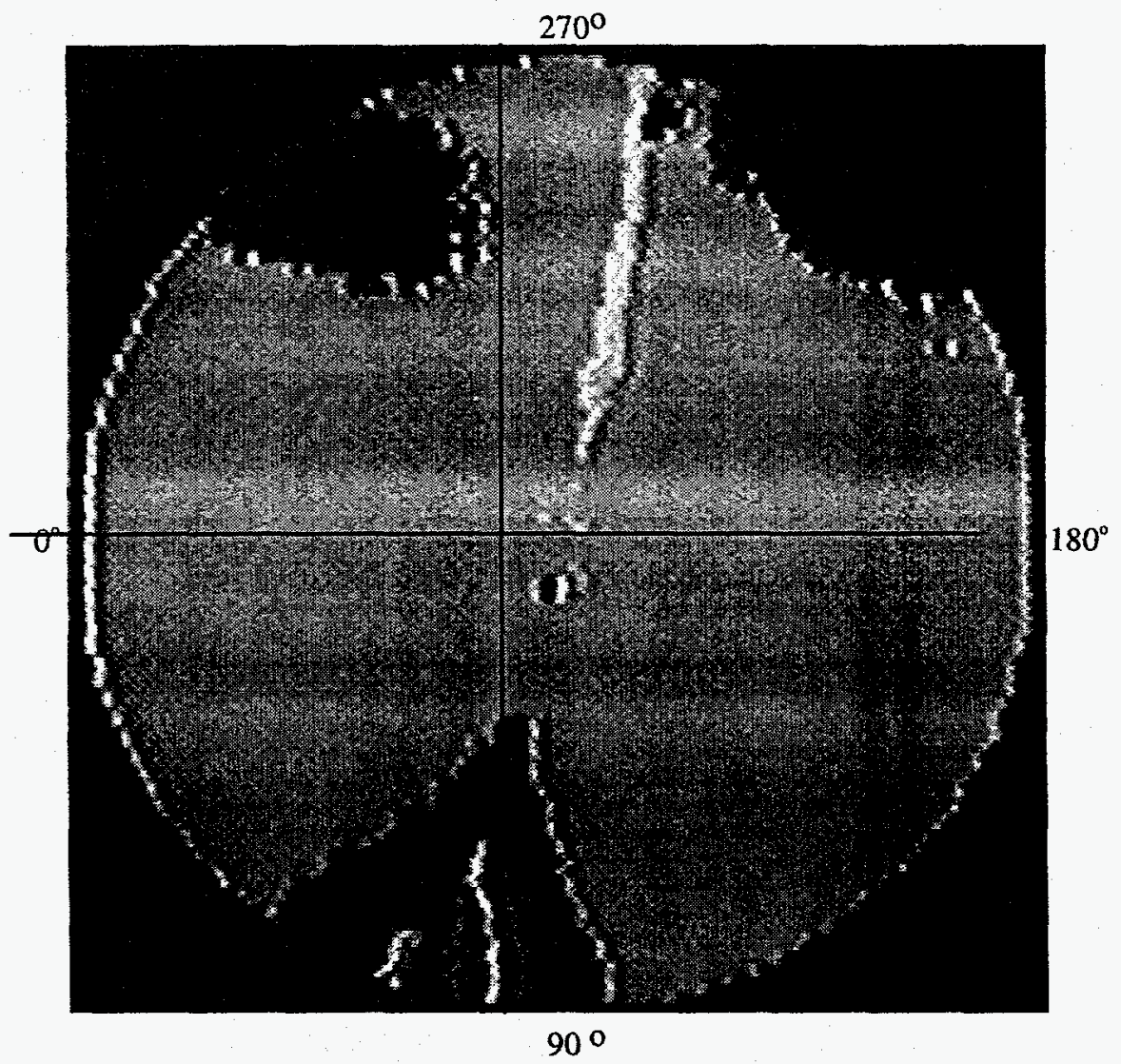

Figure 11. Surface Map of Tilted Flat with Compensation 


\section{SUMMARY}

Dynamic evaluation of the MAC-100 FTS system represents a significant increase in the range and accuracy over previous earlier devices and proves that such systems can be used to manufacture far off-axis mirror segments on existing diamond turning machines. Optimization of the MAC-100 was performed in two independent tests: improving the controller gains and adding a compensation module to reduce the nonlinearities of the controller. Both provided significant improvements.

Improving the controller gains resulted in a $51 \%$ reduction in form error running at $8 \mathrm{kHz}$ sampling speed. Adding the compensator reduced form error by $43 \%$ for full range travel, and $80 \%$ for a range of travel of $70 \mu \mathrm{m}$. However, the controller modifications resulted in a "smoother" error, while the compensator resulted in sharp anomalies that may be unsuitable for optical applications.

The control system parametric study showed that reduced spindle speed improved the P-V form error in the mirror. This is due to the additional time the controller has to react to disturbances and errors sensed by the feedback sensor. The form error appears to follow a second order polynomial relationship with spindle speed. At very low speeds, the form error still appears to be $60 \%$ of that cut at $1000 \mathrm{rpm}$. Reducing the speed, however, may be undesirable in a production environment.

Form accuracy in the diamond turned aspheric mirror is well within 1 micrometer peak-to-valley. With addition of nonlinear compensators and other control system enhancements, figure accuracy can be further improved. Such mirrors can immediately be used for infrared designs and, with minimum post polishing to enhance surface smoothness, will be useful for many applications within the visible wavelengths.

\section{ACKNOWLEDGMENTS}

Research was in part sponsored by the Ballistic Missile Defense Organization, through the System Integration, Command and Control Directorate, Integration Support Division, under Interagency Agreement No. 1855-1562-A1 with Lockheed Martin Energy Systems, Inc. under contract DE-AC05-84OR21400 with the U.S. Department of Energy. Research is also due in part to a NASA sponsored Small Business Technology Transfer project with Geltech, Inc., Orlando, Fla.

The submitted manuscript has been authored by a contractor of the U.S. Government under Contract No. DE-AC0584OR21400. Accordingly, the U.S. Government retains a nonexclusive, royalty-free license to publish or reproduce the published form of this contribution, or allow others to do so, for U.S. Government purposes.

The authors acknowledge the Precision Engineering Center of the North Carolina State University for their close collaboration in the development and performance testing of the device.

\section{REFERENCES}

[1] Miller, A. C., "Single Point Diamond Turning Process Development," Optical Fabrication \& Testing Workshop, 1992 Technical Digest Series Vol. 24, pp. 22-25, Optical Society of America.

[2] Douglas, S. S., Green, W., "Machine tool control system for turning nonaxisymmetric surfaces," Proceedings of the Joint Automatic Control Conference, AICHE, June 1979.

[3] Patterson, S. R., Magreb, E. B., "Design and testing of a fast tool servo for diamond turning," Precision Engineering, Vol. 7, No. 3, pp. 123-128, July 1985.

[4] Falter, P. J., Dow, T. A., "A diamond turning apparatus for fabrication of non-rotationally symmetric surfaces," Proceedings of the International Congress for Ultraprecision Technology, M. Weck, ed., Aachen, Germany, pp. 187-201, May 1988.

[5] Fawcett, S. C., "Small amplitude vibration compensation for precision diamond turning," Precision Engineering, Vol. 12, No. 2, April 1990. 
[6] Moorefield, II, G. M., et al., "Generation of Rotationally Asymmetric Optical Surfaces Using a Fast Tool Servo," ASPE Annual Conference Proceedings, Vol. 10, pp. 45-48, 1994.

[7] Miller, M. H., et al., "Controller design for a modern diamond turning machine," ASPE Annual Conference Proceedings, Vol. 4, pp. 62-65.

\section{DISCLAIMER}

This report was prepared as an account of work sponsored by an agency of the United States Government. Neither the United States Government nor any agency thereof, nor any of their employees, makes any warranty, express or implied, or assumes any legal liability or responsibility for the accuracy, completeness, or usefulness of any information, apparatus, product, or process disclosed, or represents that its use would not infringe privately owned rights. Reference herein to any specific commercial product, process, or service by trade name, trademark, manufacturer, or otherwise does not necessarily constitute or imply its endorsement, recommendation, or favoring by the United States Government or any agency thereof. The views and opinions of authors expressed herein do not necessarily state or reflect those of the United States Government or any agency thereof. 


\section{DISCLAMMIER}

Portions of this document may be illegible in electronic image products. Images are produced from the best available original document. 